\title{
New route to specialisation unity at last?
}

Steve Beningfield MB ChB, FFRad D (SA)

Department of Radiology Groote Schuur Hospital and University of Cape Town
$\mathrm{U}_{\mathrm{t}}$ p to the end of 2003, the Department of Education paid substantial subsidies to the universities for every successful graduate, including those obtaining Colleges of Medicine qualifications. From 2004, only university academic degrees but not College qualifications have been subsidised, meaning a significant potential loss of income to the universities unless an MMed or equivalent is also obtained by College graduates.

This policy change may serve as a catalyst in resolving the longstanding issues around the dual processes of professional certification for all specialties, namely the MMed and College routes. There is now a concerted move to create a unified examination system at all South African universities.

The proposed exam sequence will most likely be similar for all specialties.

1. The part one College examination, as before. There would not necessarily be a separate part one MMed examination.

2. An obligatory MMed programme, involving:

- A coursework element comprising courses on, inter alia, evidence-based medicine, critical reading, statistics, research methodology and the art (and sweat!) of writing articles. A generic group of programmes for all specialists is proposed, but allowance will be made for specialty-specific courses.

- A thesis to be examined and approved by external examiners, of a level that is potentially publishable.

3. Depending on individual Colleges, entry into the part two College examination may be subject to completion of the MMed coursework and thesis.

4. Only after passing the College part two examination and the MMed will registration with the Health Professions Council of South Africa as a specialist be possible.

In the end, both College and MMed (possibly alternatively designated, e.g. MPhil) degrees will be awarded.

The advantages of this system would be a single national process of specialisation, and promotion of broader skill development, including critical enquiry and academic writing. This system should also benefit our local journals, including the $S A J R$, by supplying them with articles.

However, specific radiology-related skills may warrant inclusion in the courses offered, including general computer literacy, preparation and delivery of imaging presentations, consultancy skills and business and financial concepts. Although the more theoretical computer aspects are covered in Medical Physics, Word, Excel and PowerPoint familiarity is surely very relevant to us. The fear of 'contaminating' the pure academic environment with practical life skills is surely unfounded. Don't we all wish we had been taught more business and accounting proficiency at school? 


\section{EDITORIAL}

Consistency in the coursework elements between radiology departments at all universities would be highly desirable, creating a golden opportunity for those interested to come together and review the existing processes. Similarly, the debate concerning a 4-year versus 5-year training schedule, the correct timing and nature of anatomy and physics training, and the possibility of postgraduate Fellowships could be explored.

Recently the South African College of Radiology has permitted physics and anatomy credits to be carried to the next examination. The Royal College has recently changed its medical physics examination, which now takes place before entry into hospital training, principally to ensure that radiation protection and safety concepts are known to the new registrars. The topics covered are therefore directed at more conventional radiological imaging, avoiding high-tech subjects such as MRI. Conversely, anatomy has been relocated to their final examination, on the basis that much anatomy is learned while undergoing clinical radiology training. The counter argument is that learning the anatomy earlier allows one to benefit more from clinical training.

The opportunity for restructuring the training received by our registrars by including both more academic and practical exposure in a more formalised setting is very promising and will hopefully be addressed at a workshop attended by all interested parties in 2005 .

\section{Steve Beningfield}

Guest Editor 